\title{
Article
}

\section{Bacteria filtration efficiency of different face masks worn during COVID-19 pandemic in north-eastern Tanzania: An in vitro study}

\author{
Marianne Gnanamuttupulle 1,2,*, Shilanaiman Hilary Ntundu 1,2, Oliver Henke 3, \\ Abias Anthon Moshi ${ }^{4}$, David Msuya 1,2, Kondo Chilonga 1,2 and Samuel G. Chugulu 1,2 \\ ${ }^{1}$ Department of General Surgery, Kilimanjaro Christian Medical Centre, P.O.Box 3010, Moshi, Tanzania. \\ ${ }^{2}$ Kilimanjaro Christian Medical University College, P.O.Box 2240, Moshi, Tanzania. \\ ${ }^{3}$ Cancer Care Centre, Kilimanjaro Christian Medical Centre, P.O.Box 3010, Moshi, Tanzania. \\ ${ }^{4}$ Microbiology Department, Catholic University of Health and Allied, Sciences, Bugando,P.O.Box 1464, \\ Mwanza, Tanzania. \\ *Correspondence: drmarianne.pulle@gmail.com
}

\begin{abstract}
Increased demand for wearing face masks, lack of surgical masks and N95 respirators during the coronavirus pandemic created alternative needs for cloth masks. Therefore, to determine filtration efficacy, reusability and duration of wearing new and hand washed cloth masks, the bacteria filtration efficacy was tested using Staphylococcus aureus and Escherichia coli. Cotton cloth masks; single layer without pleats and with pleats, double layer with canvas filter in the middle, double layer with stiff filter in the middle, double layer with pleats on both sides and locally made and imported surgical masks and N95 respirators were used. Bacterial suspension was sprayed over outer surface and swabbed from inner surface at $0 \mathrm{hrs}, 4^{\mathrm{th} h r}, 8^{\text {th hr}}$ and $12^{\text {th }} \mathrm{hr}$. Similar procedure was performed to hand washed and ironed cotton cloth masks. After 24 hours of incubation, single layer without pleats and with pleats had no filtration efficacy $(0-100 \%)$. Double layer with stiff filter in the middle and double layer with pleats on both sides had higher filtration efficacy $(99.96-100 \%)$, this filtration efficacy remained up to three occasions of hand washing with soap and water, conferring protection up to 12 hours. Filtration efficacy of surgical masks made locally, imported and N95 respirators were $90-100 \%, 99.99-100 \%$, and $99.99-100 \%$ respectively.
\end{abstract}

Keywords: SARS-CoV-2; COVID-19; face masks; filtration efficiency; Tanzania

\section{Introduction}

The confirmation of the index case of the novel coronavirus disease (COVID-19) due to Severe Acute Respiratory Syndrome Coronavirus-2 (SARS-CoV-2) in December 2019[1] has led to a halt in the routine daily lives in many countries including Tanzania. As the virus crossed the boundaries of China and spread across the globe, the World Health Organization (WHO) on the $11^{\text {th }}$ of March 2020 declared that COVID-19 was a pandemic[1]. Several preventive measures both personal and community based were implemented by the WHO and United States Centre for Disease Control and Prevention (CDC) with strict emphasis on frequent hand washing with soap and water or an alcohol based rub, avoid touching eyes, nose and mouth which could be potential viral entry points, cover mouth during coughing and sneezing, social distancing of 2 meter apart and to wear a face mask when in public places and when sick[2].These preventive measures were implemented following evidence that respiratory droplets and person to person contact were suggestive as the route of transmission [3]. Though the virus gene sequence was identified and diagnostic methods were established a cure for COVID-19 is yet under research. Thus, prevention has become the corner stone in battling the virus.

Following diagnosing the first patient within Tanzania in March 2020, the government advocated hand hygiene and social distancing to curb the spread of the disease [4].While surgical 
masks and N95 respirators were reserved to the healthcare workers and symptomatic patients as in line with the recommendations by the WHO and CDC [5] the general public in Tanzania use cloth face masks as a preventive barrier in public places where social distancing measures have been challenging. In regards to the increasing high demands of cloth face masks in the country various types of cloth facemask have been produced. Though the efficiency of different types of cloth materials, single versus multi layered masks and their filtration properties against respiratory droplets are been studied in several countries around the globe, none of the locally made surgical and cotton cloth face masks have been tested in a clinical trial in the country.

The coronavirus is a RNA virus is $60 \mathrm{~nm}$ to $140 \mathrm{~nm}$ in diameter and has spike like projections on its surface [6]. As respiratory droplets (particles with a diameter of $>5-10 \mu \mathrm{m}$ ) have become a potential mode of transmission, when an individual is within $1 \mathrm{~m}$ from an infected person [7], the CDC suggests that cotton cloth face masks when worn in public can slow the spread of the virus and prevent transmission of the virus from symptomatic and pre-symptomatic individuals [8]. Therefore, taking to account the recent findings in regards to the COVID-19 viral infection our study intends to utilize the bacterial properties namely the size of Staphylococcus aureus (average size 0.5-1.0 $\mu \mathrm{m}$ ) and Escherichia coli $(1.1-1.5 \mu \mathrm{m})$ in relation to the size of the respiratory droplets produced by the COVID-19 infected patient, to assess the efficiency of the filtration properties of the cotton cloth face masks [9].

\section{Materials and Methods}

\subsection{Study design}

The study was performed at Kilimanjaro Christian Medical University College laboratory as an in-vitro study. The bacteria filtration efficacy (BFE) was used to evaluate the cotton cloth face masks, surgical masks and the N95 respirators in the study by using two microorganisms namely Staphylococcus aureus and Escherichia coli.

\subsection{Study area}

Kilimanjaro region and its surrounding regions has many tourist attraction sites hence many tourists visit the country through this region. Furthermore, the first patient in the country with COVID-19 was diagnosed from this region the population in this community are encouraged to wear cloth face masks. Taking into account that majority of the population in the country are living under one dollar per day[10], majority of the population cannot afford to buy cloth face masks regularly. As a result a variety of reusable commercially available cotton cloth face masks have become available in the region. However, their BFE in regards to their reusability was not clinically proven thus creating a need for this study.

\subsection{Study subjects}

Different face masks made of $100 \%$ cotton cloth and medical face masks were selected as follows:

Sample 1 (S1); Single layer cotton cloth face mask without pleats.

Sample 2 (S2); Single layer cotton cloth face mask with pleats on both outer and inner layer without a middle filter layer.

Sample 3 (S3); Double layer cotton cloth face mask with a canvas filter (a non-woven fabric lining) layer between the outer and inner layer without pleats.

Sample 4 (S4); Double layer cotton cloth face mask with a stiff filter (breathable woven fabric lining) layer between the outer and inner layer without pleats.

Sample 5 (S5); Double layer cotton cloth face mask with pleats on the outer and inner layer.

The above face masks were tailored locally at the Moshi market (Makonde Garments and Tailors).

Sample 6 (S6); Locally made surgical face masks (FSPL, Tanzania)

Sample 7 (S7); Surgical face masks (BBL, China) 


\section{Sample 8 (S8); N95 respirator (Kimberly Clark Corp, USA)}

\subsection{Experimental design}

The evaluation of face masks in vivo and in vitro is most commonly experimented by the BFE method [9]. Whereby the bacteria penetrating the face mask are collected, cultured and counted to determine the number of colony forming units (CFUs) that penetrates the mask. The ability of a microorganism to penetrate a face mask depends mainly on the shape, size and the surface characteristic of the organism. Thus, S.aureus a gram-positive cocci with an average diameter of $0.5 \mu \mathrm{m}-1.0 \mu \mathrm{m}$ was selected to evaluate the BFE in our study[9]. Furthermore, as the penetration ability of a rod shaped bacteria is less than a spherical shaped bacteria of the same size[9], E.coli which is gram negative rod shaped with an average diameter of $1.1 \mu \mathrm{m}-1.5 \mu \mathrm{m}$ and $2.0 \mu \mathrm{m}-6.0 \mu \mathrm{m}$ in length was also selected to evaluate the BFE [9]. In this study the BFE of the masks were evaluated using two microorganisms namely S.aureus; ATCC 25923 and E.coli; ATCC25922 (American Type Culture Collection Inc., Rockville, Md).

The bacterial suspension was sprayed onto the masks by an $8.4 \mathrm{fl} \mathrm{oz} / 250 \mathrm{ml}$ plastic spray bottle (Forever, USA) to evaluate BFE of the face masks. To maintain the normal range of human respiration and the recommended flow rate of $1 \mathrm{ft}^{3} / \mathrm{min}$ as recommended by the American Society for tropical medicine [11] two sprays were performed to every test and control face masks at 0hrs and $8 \mathrm{hrs}$ to represent an average number of times a normal person could sneeze within 4 hrs [12]. As to simulate the person wearing a facemask to prevent or slow the spread of the aerosol the spray nozzle and the centre of the outer layer of all the face masks were kept in contact to each other.

\subsection{Washing and ironing technique for the cotton face masks}

The cotton face masks were washed with clean running tap water and soap (locally made soap brand 'Jamaa'). Then the masks were soaked for 30minutes followed by rinsing and scrubbing them trice with clean tap water. The masked were air dried in the sun and lastly each mask was ironing (brand; Philips iron, Level of heat; maximum heat for cotton fabric) for up to 30 seconds. This process was repeated for 3 consecutive days to mimic a daily scenario of an individual using a face mask.

\subsection{Laboratory procedures}

According to the samples described in the study the masks were arranged into two sets as before washing and after washing and labelled accordingly. The two separate bacterial suspensions (S.aureus and E.coli) consisted of normal saline ( $\mathrm{NaCl} ; 0.9 \% \mathrm{w} / \mathrm{v}$ [Aculife Healthcare, India]) and test bacteria were prepared by keeping the turbidity equal to 0.5 MacFarland [9] using both visual comparison to turbidity standards and a Densichek photometer (bioMérieux). A 0.5 MacFarland standard inoculum was prepared from $24 \mathrm{hrs}$ culture using a Blood Agar (BA) media (Oxoid LTD, England) made from $7 \%$ sheep blood and incubate at $37^{\circ} \mathrm{C}$ at ambient air. Since cloth masks were locally manufactured and the surgical and N95 were industrial manufactured to be sure that all the sample(S1-8) were sterile, sterilization were done to all masks using autoclave (Nüve, Turkey) with a temperature of $121^{\circ} \mathrm{C}$ and pressure of $15 \mathrm{lbs}$ for 15 minutes. Autoclave control tapes were used to ensure effective sterilization and to prevent all possibilities of contamination from the manufacturer. Then each test mask was sprayed twice. Regular sterile cotton swabs (Medico, China) were dipped in sterile normal saline $(\mathrm{NaCl} ; 0.9 \% \mathrm{w} / \mathrm{v}$ [Aculife Healthcare, India]) prior to each swabbing. The control arm of the cotton cloth face masks before and after washing, the surgical masks and the N95 respirators were swabbed on the sprayed surface of each mask while the test arm of the cotton cloth face masks before and after washing, the surgical masks and N95 respirators were swabbed on the unsprayed inner surface. Both procedures were performed immediately at 0hrs followed by $4 \mathrm{hr}$, $8 \mathrm{hrs}$ and $12 \mathrm{hrs}$. The bacteria on the sterile swab was then inoculated onto the surface of the agar plate contain BA and using sterile plastic loops of 1ul the inoculation was streaked by spreading it on the 
BA which was then followed by $24 \mathrm{hrs}$ incubation at $37^{\circ} \mathrm{C}$ in an incubator (Memmert Medico, UK) [9].

\subsection{Quality control}

\subsubsection{Media sterility}

A sterility test was done by randomly selecting $10 \%$ of the prepared media and incubating in the incubator (Memmert, Medico UK) at $37^{\circ} \mathrm{C}$ for $24 \mathrm{hrs}$. After $24 \mathrm{hrs}$ the media was interpreted and the media with no growth was regarded as sterile. All of the $10 \%$ selected media had no growth and hence the whole batch was considered sterile.

\subsubsection{Media performance}

A performance test was conducted by culturing the two test bacteria S.aureus and E.coli on four plates of the prepared media and incubated for $24 \mathrm{hrs}$. After $24 \mathrm{hrs}$, the incubated plates were read and interpreted. Positive growths of the selected isolates were regarded as a good performance media.

\subsubsection{Suspension control}

The isolate suspension that was made in comparison to the turbidity of 0.5 McFarland was tested to ensure the validity of the test organism by culturing one drop of the suspension and spreading it above the plate using a $1 \mu \mathrm{l}$ sterile disposable plastic loop and media was incubated at $37^{\circ} \mathrm{C}$ for $24 \mathrm{hrs}$ and interpreted. A growth more than $10^{5} \mathrm{CFUs}$ of the organisms were regarded as reliable for the study.

A duplicate bacteria culture was performed to represent each design of the face mask (S1-S8) for every type of bacteria strain (S.aureus/E.coli) and each was performed on the same manner and same interval of time as for the test organism ( $0 \mathrm{hrs}, 4 \mathrm{hrs}, 8 \mathrm{hrs}$ and $12 \mathrm{hrs}$.).In vitro test uses positive and negative control to determine the initial number of bacteria. The control was prepared by inoculating $125 \mu \mathrm{l}$ of $0.5 \mathrm{MacFarland}$ S.aureus; ATCC25923 and E.coli; ATCC25922 (volume of single spray by $250 \mathrm{ml}$ plastic spray bottle).To enable enumeration of colonies a serial dilution to $10^{\wedge} 6$ was used as an inoculums by inoculating $1 \mu \mathrm{l}$ of each bacteria suspension to BA media followed by $24 \mathrm{hrs}$ incubation at $37^{\circ} \mathrm{C}$ in ambient air.

\subsection{Interpretations}

In our study the total number bacterial cells observed after a $24 \mathrm{hr}$ incubation period was termed as CFUs. For each plate, colonies were counted using the Protocol Bacteria Colony Version 2.05 to obtain the CFUs counts from 0.5MacFarland E.coli and S.aureus suspensions for the test $(\mathrm{T})$ and control (C) per single $250 \mathrm{ml}$ plastic spray bottle. The results were expressed as CFUs per $125 \mathrm{ul}$ of 0.5 MacFarland E.coli and S.aureus.

Growth on culture media was determined by comparing the colony characteristics with that of positive control, i.e., colony colour, size and texture, margin and effect on plate (haemolysis). Any growth out of the streaked line was regarded as a possible contamination even if it had the same characteristics to that of the positive control. Absence of growth was determined by comparing with a negative control (un-inoculated plate). Different two independent readers observed the culture plates to determine the colony growth and number of colonies. Finally a mathematical formula was used to calculate the BFE for each face mask. \%BFE $=100(\mathrm{C}-\mathrm{T}) / \mathrm{C}$ whereby $\mathrm{C}=$ average $\mathrm{CFU}$ in a plate for test controls and $\mathrm{T}=\mathrm{CFUs}$ in a plate for the test [9].

\subsection{Data analysis}

Data collected from laboratory data collection sheet was entered in a Microsoft excel sheet (Microsoft Corporation, Redmond, WA). The BFE was expressed as a percentage of difference in CFUs between the control and the test face masks divided by CFUs of the control. 


\subsection{Selection of face masks}

Cotton cloth face masks which were made locally with the following qualities; single layer cotton cloth face mask without pleats, single layer cotton cloth face mask with pleats, double layer cotton cloth face mask with a canvas filter layer between the outer and inner layer without pleats, double layer cotton cloth face mask with a stiff filter layer between the outer and inner layer, double layer cotton cloth face mask with pleats on the outer and inner layer. Medical masks; locally made surgical face masks (FSPL, Tanzania), surgical masks (BBL, China) and N95 respirators (Kimberly Clark Corp, USA).

All face masks which were damaged following sterilization were excluded from the study.

\section{Results}

The single layer cotton cloth face masks before washing had a $92.31 \%, 90 \%, 99.87 \%$ and $99.99 \%$ BFE at $0 \mathrm{hrs}$, $4 \mathrm{hrs}, 8 \mathrm{hrs}$ and $12 \mathrm{hrs}$ respectively. Following washing the BFE at $0 \mathrm{hrs}$ was $99.92 \%$, $4 \mathrm{hrs}$ and 8 hrs was $99.99 \%$ while at 12 hrs was $90 \%$ (Table 1 ).

Table 1. Single layer cotton cloth face mask without pleats (Sample 1).

\begin{tabular}{|c|c|c|c|c|c|c|c|}
\hline \multirow[t]{2}{*}{ Time } & \multirow{2}{*}{$\begin{array}{c}\text { Bacterial } \\
\text { Growth }\end{array}$} & \multicolumn{3}{|c|}{ Before Washing } & \multicolumn{3}{|c|}{ After Washing } \\
\hline & & Control & Test & $(\%) B^{\prime} E^{*}$ & Control & Test & (\%)BFE \\
\hline \multicolumn{2}{|c|}{$\begin{array}{c}\text { Control Following } \\
\text { Sterilization }\end{array}$} & $\mathrm{NBG}^{* *}$ & NBG & & NBG & NBG & \\
\hline \multirow[t]{2}{*}{ Ohrs } & S. aureus & $13 / \mathrm{CFU}^{* * *}$ & $1 / \mathrm{CFU}$ & 92.31 & $>10^{4} / \mathrm{CFU}$ & 1/CFU & 99.99 \\
\hline & E.coli & $>10^{4} / \mathrm{CFU}$ & NBG & 100 & $>10^{4} / \mathrm{CFU}$ & 8/CFU & 99.92 \\
\hline \multirow[t]{2}{*}{ 4hrs } & S. aureus & $>10^{5} / \mathrm{CFU}$ & NBG & 100 & $>10^{5} / \mathrm{CFU}$ & $1 / \mathrm{CFU}$ & 99.99 \\
\hline & E.coli & $>10^{5} / \mathrm{CFU}$ & $>10^{4} / \mathrm{CFU}$ & 90 & $>10^{5} / \mathrm{CFU}$ & NGB & 100 \\
\hline \multirow[t]{2}{*}{8 hrs } & S. aureus & $>10^{5} / \mathrm{CFU}$ & NBG & 100 & $>10^{4} / \mathrm{CFU}$ & $1 / \mathrm{CFU}$ & 99.99 \\
\hline & E.coli & $>10^{4} / \mathrm{CFU}$ & 13 /CFU & 99.87 & 5/CFU & NBG & 100 \\
\hline \multirow[t]{2}{*}{ 12hrs } & S. aureus & $>10^{5} / \mathrm{CFU}$ & NBG & 100 & $>10^{5} / \mathrm{CFU}$ & $>10^{4} / \mathrm{CFU}$ & 90 \\
\hline & E.coli & $>10^{5} / \mathrm{CFU}$ & $1 / \mathrm{CFU}$ & 99.99 & $>10^{4} / \mathrm{CFU}$ & NBG & 100 \\
\hline
\end{tabular}

*BFE; Bacteria Filtration Efficacy, ${ }^{* *} \mathrm{NBG}$; No Bacteria Growth, ${ }^{* *} \mathrm{CFU}$; Colony Forming Units.

Before and after washing the single layer pleated mask it was evident that the bacteria were not filtered through at 0 hrs and $12 \mathrm{hrs}$ while BFE before and after washing the mask at 4 hrs was $90 \%$ whereas at $8 \mathrm{hrs}$ the BFE before and after washing the mask was $99.97 \%$ and $100 \%$ respectively (Table 2).

Table 2. Single layer cotton face mask with pleats (Sample 2).

\begin{tabular}{|c|c|c|c|c|c|c|c|}
\hline \multirow[t]{2}{*}{ Time } & \multirow[t]{2}{*}{ Bacterial Growth } & \multicolumn{3}{|c|}{ Before Washing } & \multicolumn{3}{|c|}{ After Washing } \\
\hline & & Control & Test & $(\%)$ BFE $^{*}$ & Control & Test & $(\%) B F E$ \\
\hline \multicolumn{2}{|c|}{$\begin{array}{c}\text { Control Following } \\
\text { Sterilization }\end{array}$} & $\mathrm{NBG}^{* *}$ & NBG & & NBG & NBG & \\
\hline \multirow[t]{2}{*}{ Ohrs } & S. aureus & $>10^{4} / \mathrm{CFU}^{* * *}$ & $8 / \mathrm{CFU}$ & 99.92 & $>10^{4} / \mathrm{CFU}$ & $8 / \mathrm{CFU}$ & 99.92 \\
\hline & E.coli & $>10^{4} / \mathrm{CFU}$ & $>10^{4} / \mathrm{CFU}$ & 0 & $>10^{4} / \mathrm{CFU}$ & $>10^{4} / \mathrm{CFU}$ & 0 \\
\hline \multirow[t]{2}{*}{ 4hrs } & S. aureus & $>10^{5} / \mathrm{CFU}$ & $3 / \mathrm{CFU}$ & 99.99 & $>10^{5} / \mathrm{CFU}$ & $1 / \mathrm{CFU}$ & 99.99 \\
\hline & E.coli & $>10^{5} / \mathrm{CFU}$ & $>10^{4} / \mathrm{CFU}$ & 90 & $>10^{5} / \mathrm{CFU}$ & $>10^{4} / \mathrm{CFU}$ & 90 \\
\hline \multirow[t]{2}{*}{ 8hrs } & S. aureus & $>10^{5} / \mathrm{CFU}$ & $3 / \mathrm{CFU}$ & 99.97 & $>10^{5} / \mathrm{CFU}$ & NBG & 100 \\
\hline & E.coli & $>10^{4} / \mathrm{CFU}$ & $1 / \mathrm{CFU}$ & 99.99 & $>10^{4} / \mathrm{CFU}$ & NBG & 100 \\
\hline \multirow[t]{2}{*}{ 12hrs } & S. aureus & $>10^{5} / \mathrm{CFU}$ & $>10^{4} / \mathrm{CFU}$ & 90 & $>10^{5} / \mathrm{CFU}$ & $>10^{5} / \mathrm{CFU}$ & 0 \\
\hline & E.coli & $>10^{5} / \mathrm{CFU}$ & $>10^{5} / \mathrm{CFU}$ & 0 & $>10^{5} / \mathrm{CFU}$ & $>10^{4} / \mathrm{CFU}$ & 90 \\
\hline
\end{tabular}

${ }^{*} \mathrm{BFE}$; Bacteria Filtration Efficacy, ${ }^{* *} \mathrm{NBG}$; No Bacteria Growth, ${ }^{* * *} \mathrm{CFU}$; Colony Forming Units. 
Before washing the double layer cotton face mask with a canvas filter a $100 \%$ BFE was observed at $0 \mathrm{hrs}$ and $4 \mathrm{hrs}$ whereas at $8 \mathrm{hrs}$ and $12 \mathrm{hrs}$ the BFE was $99.99 \%$ and $90 \%$. After washing these masks the BFE at $0 \mathrm{hrs}$, $4 \mathrm{hrs}$, $8 \mathrm{hrs}$ and $12 \mathrm{hrs}$ were $100 \%, 99.99 \%, 99.92 \%$ and $0 \%$ respectively (Table 3).

Table 3. Double layer cotton cloth face mask with a canvas filter layer between the outer and inner layer without pleats (Sample 3).

\begin{tabular}{|c|c|c|c|c|c|c|c|}
\hline \multirow[t]{2}{*}{ Time } & \multirow[t]{2}{*}{ Bacterial Growth } & \multicolumn{3}{|c|}{ Before Washing } & \multicolumn{3}{|c|}{ After Washing } \\
\hline & & Control & Test & $(\%) B F E^{*}$ & Control & Test & $(\%) B F E$ \\
\hline \multicolumn{2}{|c|}{$\begin{array}{c}\text { Control Following } \\
\text { Sterilization }\end{array}$} & $\mathrm{NBG}^{* *}$ & NBG & & NBG & NBG & \\
\hline \multirow[t]{2}{*}{ 0hrs } & S. aureus & $>10^{4} / \mathrm{CFU}^{* * *}$ & NBG & 100 & $>10^{4} / \mathrm{CFU}$ & NBG & 100 \\
\hline & E.coli & $>10^{4} / \mathrm{CFU}$ & NBG & 100 & $>10^{4} / \mathrm{CFU}$ & NBG & 100 \\
\hline \multirow[t]{2}{*}{ 4hrs } & S. aureus & $>10^{4} / \mathrm{CFU}$ & NBG & 100 & $>10^{5} / \mathrm{CFU}$ & $1 / \mathrm{CFU}$ & 99.99 \\
\hline & E.coli & $>10^{5} / \mathrm{CFU}$ & NBG & 100 & $>10^{5} / \mathrm{CFU}$ & NBG & 100 \\
\hline \multirow[t]{2}{*}{$8 \mathrm{hrs}$} & S. aureus & $>10^{4} / \mathrm{CFU}$ & $1 / \mathrm{CFU}$ & 99.99 & $>10^{4} / \mathrm{CFU}$ & $8 / \mathrm{CFU}$ & 99.92 \\
\hline & E.coli & $>10^{4} / \mathrm{CFU}$ & NBG & 100 & $>10^{4} / \mathrm{CFU}$ & NBG & 100 \\
\hline \multirow[t]{2}{*}{$12 \mathrm{hrs}$} & S. aureus & $>10^{5} / \mathrm{CFU}$ & $>10^{4} / \mathrm{CFU}$ & 90 & $>10^{4} / \mathrm{CFU}$ & $>10^{4} / \mathrm{CFU}$ & 0 \\
\hline & E.coli & $>10^{5} / \mathrm{CFU}$ & NBG & 100 & $>10^{5} / \mathrm{CFU}$ & $>3 / \mathrm{CFU}$ & 99.99 \\
\hline
\end{tabular}

*BFE; Bacteria Filtration Efficacy, ${ }^{* *} \mathrm{NBG}$; No Bacteria Growth, ${ }^{* *} \mathrm{CFU}$; Colony Forming Units.

The double layer cotton face masks with a stiff filter layer had 100\% BFE before and after washing at both $4 \mathrm{hrs}$ and $8 \mathrm{hrs}$ and $99.99 \%$ at $12 \mathrm{hrs}$. Whereas at 0 hrs the BFE was $100 \%$ and $99.98 \%$ before and after washing the masks respectively (Table 4).

Table 4. Double layer cotton cloth face mask with a stiff filter layer between the outer and inner layer without pleats (Sample 4).

\begin{tabular}{|c|c|c|c|c|c|c|c|}
\hline \multirow[t]{2}{*}{ Time } & \multirow[t]{2}{*}{ Bacterial Growth } & \multicolumn{3}{|c|}{ Before Washing } & \multicolumn{3}{|c|}{ After Washing } \\
\hline & & Control & Test & $(\%) \mathrm{BFE}^{*}$ & Control & Test & $(\%) B F E$ \\
\hline \multicolumn{2}{|c|}{ Control Following Sterilization } & $\mathrm{NBG}^{* *}$ & NBG & & NBG & NBG & \\
\hline \multirow[t]{2}{*}{ Ohrs } & S. aureus & $>10^{4} / \mathrm{CFU}^{* * *}$ & NBG & 100 & $>10^{4} / \mathrm{CFU}$ & $2 / \mathrm{CFU}$ & 99.98 \\
\hline & E.coli & $>10^{4} / \mathrm{CFU}$ & NBG & 100 & $>10^{4} / \mathrm{CFU}$ & NBG & 100 \\
\hline \multirow[t]{2}{*}{ 4hrs } & S. aureus & $>10^{4} / \mathrm{CFU}$ & NBG & 100 & $>10^{4} / \mathrm{CFU}$ & NBG & 100 \\
\hline & E.coli & $>10^{4} / \mathrm{CFU}$ & NBG & 100 & $>10^{5} / \mathrm{CFU}$ & NBG & 100 \\
\hline \multirow[t]{2}{*}{8 hrs } & S. aureus & $>10^{5} / \mathrm{CFU}$ & NBG & 100 & $>10^{4} / \mathrm{CFU}$ & NBG & 100 \\
\hline & E.coli & $>10^{4} / \mathrm{CFU}$ & NBG & 100 & $2 / \mathrm{CFU}$ & NBG & 100 \\
\hline \multirow[t]{2}{*}{ 12hrs } & S. aureus & $>10^{5} / \mathrm{CFU}$ & $1 / \mathrm{CFU}$ & 99.99 & $>10^{5} / \mathrm{CFU}$ & $4 / \mathrm{CFU}$ & 99.99 \\
\hline & E.coli & $>10^{5} / \mathrm{CFU}$ & NBG & 100 & $>10^{4} / \mathrm{CFU}$ & NBG & 100 \\
\hline
\end{tabular}

*BFE; Bacteria Filtration Efficacy, ${ }^{* *} \mathrm{NBG}$; No Bacteria Growth, ${ }^{* *} \mathrm{CFU}$; Colony Forming Units.

The double layer cloth face mask with pleats before and after washing had a 100\% BFE at 4 hrs and $99.99 \%$ at $12 \mathrm{hrs}$. At 0 hrs and $8 \mathrm{hrs}$ the BFE $99.97 \%$ and $100 \%$ respectively before washing the masks and following washing the BFE at 0hrs and 8 hrs was $99.96 \%$ and $99.99 \%$ respectively (Table 5). 
Table 5. Double layer cotton cloth face mask with pleats on the outer and inner layer (Sample 5).

\begin{tabular}{|c|c|c|c|c|c|c|c|}
\hline \multirow[t]{2}{*}{ Time } & \multirow[t]{2}{*}{ Bacterial Growth } & \multicolumn{3}{|c|}{ Before Washing } & \multicolumn{3}{|c|}{ After Washing } \\
\hline & & Control & Test & $(\%) B^{\prime} E^{*}$ & Control & Test & (\%)BFE \\
\hline \multicolumn{2}{|c|}{ Control Following Sterilization } & $\mathrm{NBG}^{* *}$ & NBG & & NBG & NBG & \\
\hline \multirow[t]{2}{*}{ Ohrs } & S. aureus & $>10^{4} / \mathrm{CFU}^{* * *}$ & NBG & 100 & $>10^{4} / \mathrm{CFU}$ & $2 / \mathrm{CFU}$ & 99.98 \\
\hline & E.coli & $>10^{4} / \mathrm{CFU}$ & $3 / \mathrm{CFU}$ & 99.97 & $>10^{4} / \mathrm{CFU}$ & $4 / \mathrm{CFU}$ & 99.96 \\
\hline \multirow[t]{2}{*}{ 4hrs } & S. aureus & $>10^{5} / \mathrm{CFU}$ & NBG & 100 & $>10^{4} / \mathrm{CFU}$ & NBG & 100 \\
\hline & E.coli & $1 / \mathrm{CFU}$ & NBG & 100 & $>10^{5} / \mathrm{CFU}$ & NBG & 100 \\
\hline \multirow[t]{2}{*}{ 8hrs } & S. aureus & $>10^{4} / \mathrm{CFU}$ & NBG & 100 & $>10^{5} / \mathrm{CFU}$ & NBG & 100 \\
\hline & E.coli & $1 / \mathrm{CFU}$ & NBG & 100 & $>10^{4} / \mathrm{CFU}$ & $1 / \mathrm{CFU}$ & 99.99 \\
\hline \multirow[t]{2}{*}{ 12hrs } & S. aureus & $>10^{4} / \mathrm{CFU}$ & $1 / \mathrm{CFU}$ & 99.99 & $>10^{5} / \mathrm{CFU}$ & 5/CFU & 99.99 \\
\hline & E.coli & $>10^{5} / \mathrm{CFU}$ & $5 / \mathrm{CFU}$ & 99.99 & $>10^{5} / \mathrm{CFU}$ & NBG & 100 \\
\hline
\end{tabular}

*BFE; Bacteria Filtration Efficacy, ${ }^{* *} \mathrm{NBG}$; No Bacteria Growth, ${ }^{* * *} \mathrm{CFU}$; Colony Forming Units.

The locally made surgical masks had a BFE of $90 \%$ at both 0 hrs and 4 hrs. The BFE of $0 \%$ and $100 \%$ were reported at $8 \mathrm{hrs}$ and $12 \mathrm{hrs}$ respectively (Table 6).

Table 6. Locally made surgical face masks (Sample 6).

\begin{tabular}{|c|c|c|c|c|}
\hline Time & Bacterial Growth & Control & Test & $(\%)$ BFE* $^{*}$ \\
\hline \multicolumn{2}{|c|}{ Control Following Sterilization } & $\mathrm{NBG}^{* *}$ & NBG & \\
\hline \multirow[t]{2}{*}{ Ohrs } & S. aureus & $>10^{4} / \mathrm{CFU}^{* * *}$ & $3 / \mathrm{CFU}$ & 99.97 \\
\hline & E.coli & $>10^{5} / \mathrm{CFU}$ & $>10^{4} / \mathrm{CFU}$ & 90 \\
\hline \multirow[t]{2}{*}{ 4hrs } & S. aureus & $>10^{5} / \mathrm{CFU}$ & NBG & 100 \\
\hline & E.coli & $>10^{5} / \mathrm{CFU}$ & $>10^{4} / \mathrm{CFU}$ & 90 \\
\hline \multirow[t]{2}{*}{$8 \mathrm{hrs}$} & S. aureus & $>10^{5} / \mathrm{CFU}$ & NBG & 100 \\
\hline & E.coli & $>10^{5} / \mathrm{CFU}$ & NBG & 100 \\
\hline \multirow[t]{2}{*}{ 12hrs } & S. aureus & $>10^{5} / \mathrm{CFU}$ & $>10^{5} / \mathrm{CFU}$ & 0 \\
\hline & E.coli & $>10^{5} / \mathrm{CFU}$ & $>10^{5} / \mathrm{CFU}$ & 0 \\
\hline
\end{tabular}

*BFE; Bacteria Filtration Efficacy, ${ }^{* *} \mathrm{NBG}$; No Bacteria Growth, ${ }^{* * *} \mathrm{CFU}$; Colony Forming Units.

The BFE was $100 \%$ at $0 \mathrm{hrs}$, $8 \mathrm{hrs}$ and $12 \mathrm{hrs}$ in the imported surgical masks and at 4 hrs the BFE was $99.99 \%$ (Table 7 ).

Table 7. Surgical face masks (Sample 7).

\begin{tabular}{|c|c|c|c|c|}
\hline Time & Bacterial Growth & Control & Test & $(\%) B^{\prime} E^{*}$ \\
\hline \multicolumn{2}{|c|}{ Control Following Sterilization } & $\mathrm{NBG}^{* *}$ & NBG & \\
\hline \multirow[t]{2}{*}{ Ohrs } & S. aureus & $>10^{5} / \mathrm{CFU}^{* * *}$ & NBG & 100 \\
\hline & E.coli & $>10^{5} / \mathrm{CFU}$ & NBG & 100 \\
\hline \multirow[t]{2}{*}{ 4hrs } & S. aureus & $>10^{5} / \mathrm{CFU}$ & $1 / \mathrm{CFU}$ & 99.99 \\
\hline & E.coli & $>10^{5} / \mathrm{CFU}$ & $4 / \mathrm{CFU}$ & 99.99 \\
\hline \multirow[t]{2}{*}{$8 \mathrm{hrs}$} & S. aureus & $>10^{5} / \mathrm{CFU}$ & NBG & 100 \\
\hline & E.coli & $>10^{5} / \mathrm{CFU}$ & NBG & 100 \\
\hline \multirow[t]{2}{*}{ 12hrs } & S. aureus & $>10^{5} / \mathrm{CFU}$ & NBG & 100 \\
\hline & E.coli & $>10^{5} / \mathrm{CFU}$ & NBG & 100 \\
\hline
\end{tabular}

*BFE; Bacteria Filtration Efficacy, ${ }^{* *} \mathrm{NBG}$; No Bacteria Growth, ${ }^{* * *} \mathrm{CFU}$; Colony Forming Units. 
The N95 respirator had 100\% BFE at 0hrs, 8hrs and 12hrs. Nevertheless a BFE of $99.99 \%$ was noted at 4 hrs (Table 8$)$.

Table 8. N95 respirator (Sample 8).

\begin{tabular}{|c|c|c|c|c|}
\hline Time & Bacterial Growth & Control & Test & $(\%) \mathrm{BFE}^{*}$ \\
\hline \multicolumn{2}{|c|}{ Control Following Sterilization } & $\mathrm{NBG}^{* *}$ & NBG & \\
\hline \multirow[t]{2}{*}{ Ohrs } & S. aureus & $>10^{4} / \mathrm{CFU}^{* * *}$ & NBG & 100 \\
\hline & E.coli & $>10^{5} / \mathrm{CFU}$ & NBG & 100 \\
\hline \multirow[t]{2}{*}{ 4hrs } & S. aureus & $>10^{5} / \mathrm{CFU}$ & $1 / \mathrm{CFU}$ & 99.99 \\
\hline & E.coli & $>10^{5} / \mathrm{CFU}$ & $1 / \mathrm{CFU}$ & 99.99 \\
\hline \multirow[t]{2}{*}{ 8hrs } & S. aureus & $>10^{5} / \mathrm{CFU}$ & NBG & 100 \\
\hline & E.coli & $>10^{5} / \mathrm{CFU}$ & NBG & 100 \\
\hline \multirow[t]{2}{*}{ 12hrs } & S. aureus & $>10^{5} / \mathrm{CFU}$ & NBG & 100 \\
\hline & E.coli & $>10^{5} / \mathrm{CFU}$ & NBG & 100 \\
\hline
\end{tabular}

*BFE; Bacteria Filtration Efficacy, ${ }^{* *} \mathrm{NBG}$; No Bacteria Growth, ${ }^{* *} \mathrm{CFU}$; Colony Forming Units.

\section{Discussion}

During this era of the COVID-19 pandemic various designs of cloth face masks have been adopted and due to its higher cost they are been reused by the general population in Tanzania to restrict transmission of the virus in the community. The filtration efficacy of these commercially available cloth face masks before and after washing, in north-eastern Tanzania have not been clinically proven.

In our study the most effective BFE of $99.99 \%$ to $100 \%$ was identified in the double layer cotton cloth face mask with a stiff filter layer between the outer and inner layer without pleats (before washing), N95 respirators and the imported surgical masks. Similar findings were noted in studies conducted in Tanzania [11] and America [13]. This similarity is due to the properties of theses masks which consist of a middle filtering layer of electrostatically charged meltblown microfiber fabric [14].

In this study, the double layer cotton cloth face masks; double layer with pleats on both sides without a filter in the middle and double layer with stiff filter in the middle had higher BFE of $99.96 \%$ to $100 \%$. This filtration efficacy was the same up to 12 hours in both new and hand washed masks. The double layer mask with canvas filter in the middle had the same BFE in new face masks up to 12 hours but when it was washed with soap and water and ironed that BFE was only up to 8 hours. Though a study by Amour et al., [11] reported similar findings in BFE in the same type of masks at 0 hour and 4 hours, they did not report BFE on masks washed with soap and water. Higher BFE in these masks could be attributed to the cotton cloth and filter material properties [15].The BFE of these cotton cloth masks are comparable to the imported surgical masks and the N95 respirators in this study.

These finding suggest that specific cotton cloth face masks namely the double layer cotton cloth face mask with pleats on both sides and the double layer cotton cloth face mask with a stiff filter layer in the middle with no pleats can be reused after hand washing up to three times with soap and water followed by ironing them. These findings are in line with the recommendations from the American Medical Association which recommends routine washing of the face masks with soap and water $[16,17]$.

On the other hand the single layer cotton cloth face masks with no pleats had lower BFE of $90 \%$ to $100 \%$ and single layer cotton cloth face masks with pleats had a BFE of $0 \%$ to $100 \%$. These lower BFE are reported before and after hand washing the masks with soap and water. A study performed by Eikenberry et al., estimated an inward and outward cloth mask efficacy rang of $20 \%$ to $80 \%$ and $0 \%$ to $80 \%$ respectively [18]. These masks with lower BFE may not guarantee protection to the wearer.

The locally made surgical face mask, are made in an industry and had a BFE of $90 \%$ to $100 \%$ for 8 hours. Furthermore, wearing the mask for more than 8 hours decreased the BFE to $0 \%$. Amour and 
his colleagues reported BFE of $99 \%$ to $100 \%$ on a similar mask at 0 hours and 4 hours [11]. Therefore, for maximum BFE these masks are recommended to be used for up to 4 hours.

\section{Limitations}

In this study we did not take into account the ability of the mask material to resist water, size of the pores, the mask fitting on the face contour and safe use of the masks, thus we do not know how these factors would affect our results.

\section{Implications for further research}

Further studies are recommended on mask face fitting and on BFE on other types of cloth face masks used in the community.

\section{Conclusions}

Our findings suggests that the double layer cotton cloth face masks with a stiff filter layer between the outer and inner layer with no pleats and the double layer cotton cloth face masks with pleats on the outer and inner layer can provide a significant protection against respiratory droplets produced by the SAR-CoV-2 virus as they retain their filtration efficacy up to 12 hrs during a single use and repeated use following hand washing.

\section{Ethics approval and consent to participate:}

The study was approved by the research ethical committee of Kilimanjaro Christian Medical University College of Tumaini University with a certificate No.2468. There were no human participants in this laboratory based in-vitro study. The study utilized two strains of bacteria namely S.aureus; ATCC 25923 and E.coli; ATCC25922. The research was conducted according to the standard operation procedures of the laboratory at KCMUCo.

Author Contributions: Conceptualization, M.G. and S.H.N.; methodology, M.G., O.H. and S.H.N.; software, M.G. and A.A.; validation, M.G., O.H., D.M. and K.C.; formal analysis, A.A.; investigation, M.G. and A.A.; resources, S.H.N.; data curation, M.G., S.N.H. and O.H.; writing-original draft preparation, M.G.; writing-review and editing, M.G., S.H.N., O.H., D.M. and K.C.; visualization, S.H.N.; supervision, S.G.C.; project administration, M.G. and S.H.N.; funding acquisition, M.G. All authors have read and agreed to the published version of the manuscript.

Funding: This research received no external funding

Acknowledgments: The authors are grateful to Dr. Balthazar M. Nyombi (Ph.D), Nancy Kassam and the laboratory staff of Kilimanjaro Christian Medical University College for their assistance.

Conflicts of Interest: The authors declare no conflict of interest.

\section{References}

1. World Health Organization. WHO announces COVID-19 outbreak a pandemic. World Health Organization [Internet]. 2020 Mar 12. WHO, 2020b.

2. World Health Organization. Advice on the use of masks in the context of COVID-19: interim guidance, 5 June 2020. World Health Organization; 2020a.

3. Galbadage T, Peterson BM, Gunasekera RS. Does COVID-19 Spread Through Droplets Alone.Frontiers in Public Health. 2020 Apr 24;8:163.

4. Tarimo CS, Wu J. The first confirmed case of COVID-19 in Tanzania: recommendations based on lesson learned from China. Tropical Medicine and Health. 2020 Dec;48:1-3.

5. Bartoszko JJ, Farooqi MA, Alhazzani W, Loeb M. Medical masks vs N95 respirators for preventing COVID-19 in healthcare workers: A systematic review and meta-analysis of randomized trials. Influenza and other respiratory viruses.2020 Apr 4.

6. Hui DS, Zumla A. Severe acute respiratory syndrome: historical, epidemiologic, and clinical features. Infectious Disease Clinics. 2019 Dec 1;33(4):869-89. 
7. Morawska L, Cao J. Airborne transmission of SARS-CoV-2: The world should face the reality. Environment International. 2020 Apr 10:105730.

8. Howard J, Huang A, Li Z, Tufekci Z, Zdimal V, van der Westhuizen HM, von Delft A, Price A, Fridman L, Tang LH, Tang V. Face masks against COVID-19: an evidence review.

9. Leonas KK, Jones CR, Hall D. The relationship of fabric properties and bacterial filtration efficiency for selected surgical face masks. J Text Apparel TechnolManag. 2003;78:1-8.

10. World Bank Groups. Available online: https://www.worldbank.org/en/country/tanzania/overview(accessed on $18^{\text {th }}$ May 2020)

11. Amour M, Mwanga HH, Bwire GM. Invitro filtration efficiency for selected face masks to bacteria with a size smaller than SARS-CoV-2 respiratory droplet.

12. Hansen B, Mygind N. How often do normal persons sneeze and blow the nose.Rhinology. 2002 Mar;40(1):10-2.

13. Huang JT, Huang VJ. Evaluation of the efficiency of medical masks and the creation of new medical masks.Journal of international medical research. 2007 Mar;35(2):213-23.

14. Tsai P. Performance of Masks and Discussion of the Inactivation of SARS-CoV-2. Engineered Science. 2020 May 21;10:1-7.

15. MacIntyre CR, Seale H, Dung TC, Hien NT, Nga PT, Chughtai AA, Rahman B, Dwyer DE, Wang Q. A cluster randomised trial of cloth masks compared with medical masks in healthcare workers. BMJ open. 2015 Apr 1;5(4):e006577.

16. Omer SB, Malani P, Del Rio C. The COVID-19 pandemic in the US: a clinical update. Jama. 2020 May 12;323(18):1767-8.

17. Desai AN, Aronoff DM. Masks and coronavirus disease 2019 (covid-19). Jama. 2020 Apr 17

18. Eikenberry SE, Mancuso M, Iboi E, Phan T, Eikenberry K, Kuang Y, Kostelich E, Gumel AB. To mask or not to mask: Modeling the potential for face mask use by the general public to curtail the COVID-19 pandemic. Infectious Disease Modelling.2020 Apr 21. 